\title{
Impact of Solvent Selection on Phytochemical Content, Recovery of Tannin and Antioxidant Activity of Quercus Infectoria Galls
}

\author{
Nur Alisa Kamarudin' ${ }^{1}$, Norhazilah Muhamad ${ }^{1,2}$, Nik Nur Hakimah Nik Salleh ${ }^{1}$, Suat Cheng Tan ${ }^{1, *}$
}

Nur Alisa Kamarudin ${ }^{1}$, Norhazilah Muhamad $^{1,2}$, Nik Nur Hakimah Nik Salleh', Suat Cheng Tan ${ }^{1, *}$

'School of Health Sciences, Health Campus, Universiti Sains Malaysia, 16150 Kubang Kerian, Kelantan, MALAYSIA.

${ }^{2}$ Faculty of Medicine, Medical Campus, University Sultan Zainal Abidin, 20400 Kuala Terengganu, Terengganu, MALAYSIA.

\section{Correspondence}

Suat Cheng Tan

School of Health Sciences, Health

Campus, Universiti Sains Malaysia, 16150 Kubang Kerian, Kelantan, MALAYSIA.

E-mail: tansc@usm.my

History

- Submission Date: 03-06-2021;

- Review completed: 02-07-2021;

- Accepted Date: 05-07-2021.

DOI : 10.5530/pj.2021.13.153

Article Available online

http://www.phcogj.com/v13/i5

Copyright

(C) 2021 Phcogj.Com. This is an openaccess article distributed under the terms of the Creative Commons Attribution 4.0 International license.

\begin{abstract}
Introduction: Quercus infectoria (QI) is medicinal plant well known to exhibit enormous therapeutic values. The main medicinal part of $\mathrm{Q}$ plant exists in its edible nutritious gall. This study aimed to determine the effects of extraction solvents on the overall phytochemical content, recovery of tannin and antioxidant activity of the Ol galls. Methods: Two solvents of different polarity namely water and methanol, were used to extract bioactive compounds from the Ql galls using soxhlet extraction technique. Phytochemical, TLC and HPLC assays were performed to detect and quantify the extracted compounds. DPPH assay was conducted to evaluate the antioxidant potential of the extracted compounds. Results: After 6 hours of extraction at respective solvent boiling points, methanol solvent successfully generated 1.8-fold higher crude yield (34.0\%) compared to water solvent (18.9\%). Phytochemical analysis revealed that both solvent extracts contained different secondary metabolites. The methanol extract was found richer in flavonoid while the aqueous extract was found richer in phenol, tannin, gallotannin, triterpene and cardiac glycosides. Interestingly, we found that the major type of tannin presence in Ql galls was gallotannin (hydrolysable tannin) instead of phlobatannin (non-hydrolysable tannin). The quantification results demonstrated that $\mathrm{QI}$ aqueous extract contained significantly higher gallotannin $(75.0 \mu \mathrm{g} / \mathrm{mL})$ compared to QI methanol extract $(46.8 \mu \mathrm{g} / \mathrm{mL})$. Furthermore, the aqueous extract also exhibited significant higher antioxidant activity compared to the methanol extract at concentration of $2 \mu \mathrm{g} / \mathrm{mL}$. Conclusions: This study strongly support the utilization of water solvent for optimum gallotannin extraction from QI galls
\end{abstract}

Key Words: Quercus infectoria (Ql) galls, Phytochemical analysis, Tannin, Gallotannin, Antioxidant.

\section{INTRODUCTION}

Edible herbal plants are of great potential to treat various communicable and non-communicable human diseases. These medicinal herb plants contain a mixture of bioactive compounds that has unique ability to trigger specific physiological reactions in human body. ${ }^{1}$ Bioactive compounds could be found in various parts of a plant including the root, bark, leaves, flowers, seeds, nuts, legumes and galls. However, to date, the biological contents of some traditional herb plants are yet to be elucidated to affirm their medicinal effects and safe dosage for consumption.

Detailed analysis of bioactive compounds in a particular herb plant requires specific extraction procedure which is highly depending on physicochemical factors such as extraction methodology, solvent types and polarity, as well as the chemical structure of targeted bioactive compounds. ${ }^{2}$ The quantity and quality of the end product from the extraction can be sensitively affected by any of these factors, therefore, optimization of extraction strategy is imperative to ensure herb extract with high degree of accuracy and consistency. In this study, the optimal extraction solvent and strategy to isolate tannin active compounds (particularly the gallotannin) from a local medicinal plant known as Quercus infectoria (QI) was investigated.

QI galls, also known as "buah Manjakani" in Malaysia, are excrescence formed on QI oak tree as a result of stimulus by Adleria gallae-tinctoriae gall-wasp egg deposition. These edible galls are one of the popular traditional remedies that have been widely used for centuries by old folks from Asian to treat inflamed and ulcerated skin. ${ }^{3}$ The paste of QI gall also is commonly used by local population as mouth antiseptic to control inflammation when directly apply on swelling area. Besides being applied externally, QI gall extract also can be consumed as herbal drink to regain the elasticity of uterine and vagina wall after childbirth. ${ }^{4}$ Furthermore, in medical setting, it has been reported to exhibit various benefits such as for antibacterial, antioxidant and anti-cancer ${ }^{5}$. These findings had aroused great interest among researchers to extend their investigation on the biological content of QI gall, so as in present study.

The main constituents found in QI gall are tannins (50\%-70\%) with a small amount of free gallic acid and ellagic acid. ${ }^{6}$ Furthermore, QI gall also is found to contain trace amount of beta-sitosterol, amenoflavone, hexamethyl ether, isocryptomerin, calcium oxalate, methyl oleanolate, as well as gum, sugar and essential oil. ${ }^{7}$ Being the most abundantly found active compound in QI gall, tannins are believed to play significant role in the bioactivities of the QI plant. Thus, the recovery of tannins compounds from QI is particularly of interest in this study.

Tannins are a group of polyphenols that are naturally found in a variety of edible plants, including tea ${ }^{8}$, most berries ${ }^{9}$ such as strawberries, cranberries, blueberries and in some grapes. ${ }^{10}$ Tannins in these plants serve as a natural defence mechanism against pest attack or microbial infections. ${ }^{11}$ Tannins also have been reported to exert other physiological effects, such as to accelerate blood clotting, reduce

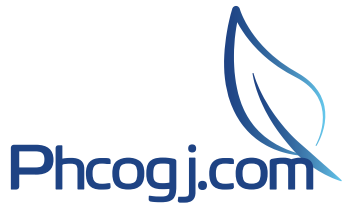

Cite this article: Kamarudin NA, Muhamad N, Salleh NNHN, Tan SC. Impact of Solvent Selection on Phytochemical Content, Recovery of Tannin and Antioxidant Activity of Quercus Infectoria Galls. Pharmacogn J. 2021;13(5):. 1195-1204 
blood pressure, decrease the serum lipid level, produce liver necrosis, modulate immunoresponses and exhibit high antioxidant potential. ${ }^{12}$ Plant tannins can be subdivided into two groups: hydrolysable tannins and non-hydrolysable tannins (or term condensed tannins). The most common hydrolysable tannin is gallotannin which is also known as tannic acid (Figure 1a). It consisted of a central glucose molecule esterified by gallic acid units (Figure 1b). On the other hand, condensed tannins are not hydrolysable. One of the most common condensed tannin is phlobatannin which is also known as phlobaphene (Figure 1c). It is oligomer or polymer composed of flavan-3-ol nucleic (Figure 1d). The presence of these two major types tannins (gallotannin and phlobatannin) in QI galls were evaluated and compared in this study.
Most tannins are polar molecules. Based on the law of similarity and intermiscibility (like dissolves like), a solute is more miscible in a solvent with similar polarity value. In other words, polar compound dissolves better in polar solvent whilst non-polar compound dissolves better in non-polar solvent. Therefore, it is imperative to use polar solvents based on tannin polarity value for optimum extraction efficiency from QI galls. Previous study had analysed the polarity of different types of solvents and listed a few common solvents from least to most polar as follow: hexane $<$ chloroform $<$ ethylacetate $<$ acetone $<$ methanol $<$ water $^{13}$. Therefore, in the present study, we employed extraction of tannins using highly polar water and methanol solvents. The water solvent was chosen as it mimics the traditional way of preparing herb

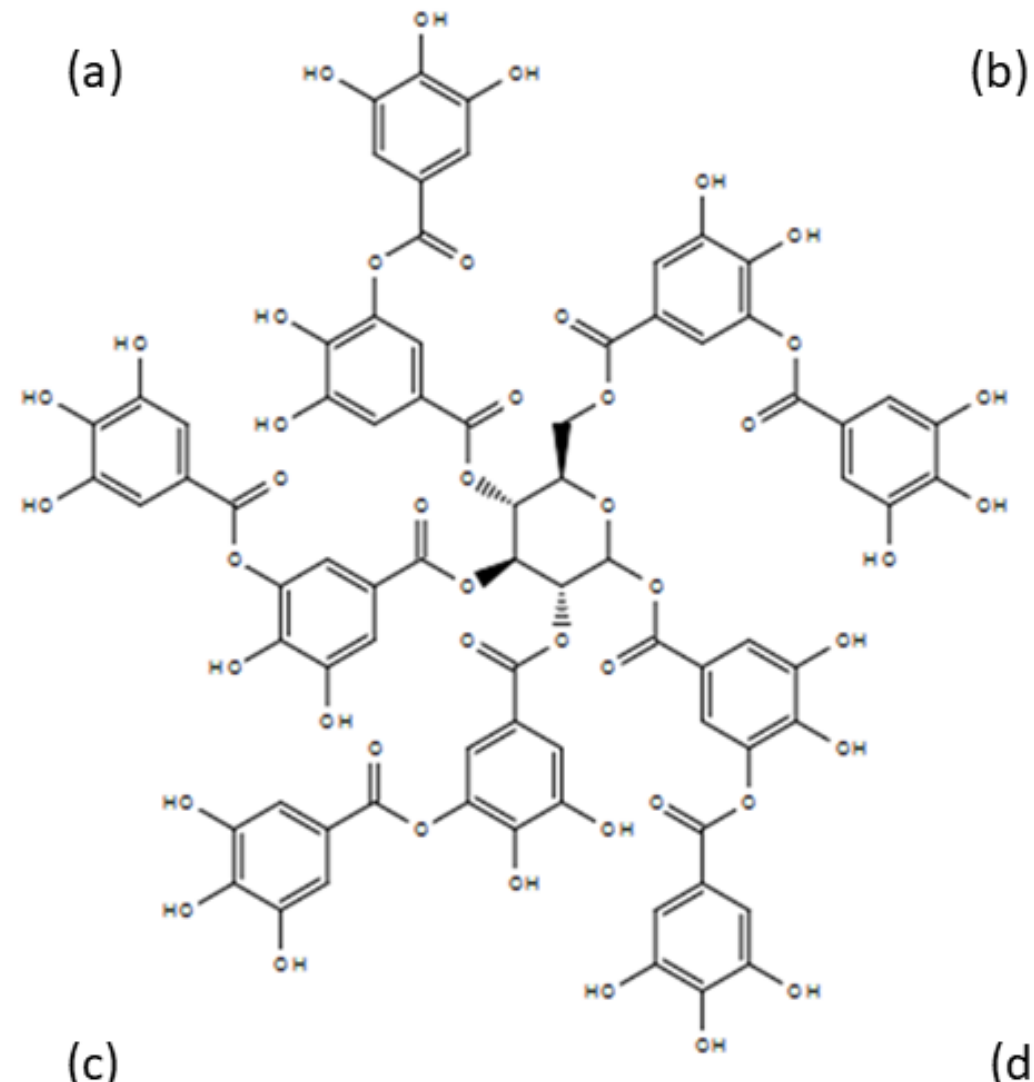<smiles>Oc1ccc(C2Oc3c(cc(O)c4c3C(C3CCC(O)CC3)C(O)C(c3ccc(O)c(O)c3)O4)CC(O)C2O)cc1O</smiles>

(d)<smiles>O=C(O)c1cc(O)c(O)c(O)c1</smiles><smiles>Oc1cc(O)c2c(c1)OC(c1cc(O)c(O)c(O)c1)C(O)C2</smiles>

Figure 1: Chemical structure of (a) gallotannin (also known as tannic acid) which is composed of (b) gallic acid units and (c) phlobatannin (also known as phlobaphene) which is composed of (d) flavan-3-ol nucleic. 
drinks while the methanol solvent was chosen because it has been generally found to be efficient in extracting lower molecular weight polyphenols. To date, there is still no study to compare the solubility of phenol, tannin, gallotannin and phlobatannin from QI galls using water and methanol solvents, as well as the effects on QI gall bioactivity. Thus, based on this background, the aim of this study was set to compare the extraction efficiency, phytochemical constituents, total tannins content and antioxidant properties exerted by these two different solvents to determine the optimum extraction method for QI galls.

\section{MATERIALS AND METHODS}

\section{Plant material authentication}

QI galls were purchased from Chinese medicine store in Kelantan, Malaysia. The source and identity of the QI galls were verified by a qualified Traditional Chinese Medicine practitioner in the store. For further scientific verification, the plant material was sent to International Islamic University Malaysia (IIUM) Herbarium Centre, Pahang, Malaysia and the verified voucher specimens (PIIUM 0229-2) was deposited in the IIUM Herbarium Centre (Supplementary material 1). The plant material was kept in dry storage area at room temperature with good ventilation to control humidity and prevent the growth of fungus until usage.

\section{Extraction of plant material}

Extraction from QI gall powder was performed using methanol and water solvents, respectively, based on previous publication with slight modifications. ${ }^{14}$

\section{(i) Methanol Extraction}

$50 \mathrm{~g}$ QI gall powder was weighed and placed in a medium-sized thimble. The thimble was put in a soxhlet extractor added with 450 $\mathrm{ml}$ of absolute methanol (Sigma, USA). Extraction was carried out at methanol boiling point $\left(\sim 64^{\circ} \mathrm{C}\right)$ for 6 hours. The solution was concentrated using rotary evaporator at $50^{\circ} \mathrm{C}$. Then the gel like paste was further air dried into powder form in a fume hood and the yield of dried extract was calculated using the following equation:

Percentage of yield extraction $(\%)=\frac{\text { Final weight }(g)}{\text { Initial weight }(g)} \times 100$

(ii) Aqueous Extraction

$50 \mathrm{~g}$ QI gall powder was weighed and placed in a medium-sized thimble. The thimble was put in a soxhlet extractor added with $450 \mathrm{ml}$ of distilled water. Extraction was carried out at water boiling point $\left(\sim 100^{\circ} \mathrm{C}\right)$ for 6 hours. The aqueous extract was subjected to rotary evaporator (Buchi AG, Flavil, Switzerland) at $50^{\circ} \mathrm{C}$ to remove excess water content and then freeze-dried into powder form. Then, the yield of extracted sample was calculated using the equation as stated in earlier section.

\section{Phytochemical analysis of QI methanol and aqueous} extracts

Phytochemical analysis tests were performed based on previously described method ${ }^{15}$ with slight modifications to detect the presence of several important active compounds in both QI extracts.

\section{(i) Detection of phenol compound}

Ferric chloride test was performed to detect the presence of phenol in both QI extracts. $0.1 \mathrm{~g}$ of extract sample was mixed with $1 \mathrm{ml}$ of distilled water. The mixture was immersed into a beaker half full with boiling distilled water until all the extract powder completely dissolved. Then, the solution was filtered using polyethersulfone (PES) membrane filter (Bioflow, Malaysia). $0.4 \mathrm{ml}$ of $1 \%$ Ferum III Chloride $\left(\mathrm{FeCl}_{3}\right)$ was added to the filtered mixture. The formation of green to blue-black solution indicated the presence of phenol. The darker the colour indicated the higher the phenol content in solution.

\section{(ii) Detection of tannins compound}

Gelatin test was performed to detect the presence of all types of tannins in general in both QI extracts. $0.1 \mathrm{~g}$ of the QI extract powder was mixed with $1 \mathrm{ml}$ of distilled water. Then, $2 \mathrm{ml}$ of $1 \%$ gelatin solution (w/v) were added in the mixture. White precipitation indicated the presence of tannins.

\section{(iii) Detection of gallotannin compound}

To detect hydrolysable tannin (gallotannin or also known as tannic acid), $0.1 \mathrm{~g}$ QI extract powder was added with $1 \mathrm{ml}$ of $5 \% \mathrm{FeCl}_{3}$ and stirred well. Formation of blue-green shading solution indicated the presence of gallotannin. The darker the colour indicated the higher the gallotannin content in sample.

\section{(iv) Detection of phlobatannin compound}

To detect non-hydrolysable tannin (phlobatannin), $0.1 \mathrm{~g}$ of QI extract powder was dissolved thoroughly with $1 \mathrm{ml}$ of distilled water in a test tube. Then $1 \mathrm{ml}$ of $1 \%$ hydrochloric acid $(\mathrm{HCl})$ was added to the test tube. Then, the test tube was immersed into a beaker half full with boiling distilled water until red precipitate was observed to confirm the presence of phlobatannin.

\section{(v) Detection of alkaloid compound}

$0.1 \mathrm{~g}$ of QI extract powder were added to $1 \mathrm{ml}$ of $1 \% \mathrm{HCl}$ in a test tube. Then, the test tube was immersed into a beaker half full with boiling distilled water until all the extract powder completely dissolved. The solution was filtered using PES membrane. A few drops of Dragendorff's reagent (Sigma, USA) were added into the filtered mixture and mixed until precipitation was observed to confirm the presence of alkaloid.

\section{(vi) Detection of flavonoid compound}

$0.1 \mathrm{~g}$ of QI extract powder was mixed with $1 \mathrm{ml}$ absolute ethanol (Sigma, USA). The mixture was warmed at $50^{\circ} \mathrm{C}$ and filtered using PES membrane filter. $1 \mathrm{ml}$ of $1 \%$ potassium hydroxide $(\mathrm{KOH})$ was carefully dropped into the mixture. The formation of dark yellow solution indicated the presence of flavonoid in extraction samples. The darker the colour indicated the higher the flavonoid content in solution.

\section{(vii)Detection of saponin compound}

$0.1 \mathrm{~g}$ of QI extract powder was dissolved with $1 \mathrm{ml}$ of distilled water. The mixture was vigorously shaken and observed for stable persistent froth. The froth from mixture was mixed with a few drops of olive oil. The appearance of emulsion was observed and recorded. Absence of froth and emulsion formation indicated absence of saponin compound.

\section{(viii) Detection of terpenoids compound}

$0.1 \mathrm{~g}$ of QI extract powder was dissolved in $1 \mathrm{ml}$ distilled water. The mixture was stirred well and filtered using PES filter membrane. The filtered mixture was mixed with $0.4 \mathrm{ml}$ chloroform $\left(\mathrm{CHCl}_{3}\right)$ and 0.6 $\mathrm{ml}$ of concentrated sulfuric acid $\left(\mathrm{H}_{2} \mathrm{SO}_{4}\right)$. Formation of reddish-brown layer interface indicated the presence of terpenoids.

\section{(ix) Detection of quinines compound}

$0.1 \mathrm{~g}$ of QI extract powder was dissolved in $1 \mathrm{ml}$ distilled water. $1 \mathrm{ml}$ of concentrated $\mathrm{HCl}$ was added and the mixture was incubated at room temperature for a minute. Yellow precipitation formation at the bottom of solution indicated the presence of quinines.

\section{(x) Detection of triterpene compound}

$1 \mathrm{ml}$ of anhydrous acetic acid $\left(\mathrm{CH}_{3} \mathrm{COOH}\right)$ was mixed with $0.5 \mathrm{mg}$ QI extract powder. The mixture was warmed at $50^{\circ} \mathrm{C}$ for a minute and the 
mixture was let cool to room temperature. $1 \mathrm{ml}$ of concentrated $\mathrm{H}_{2} \mathrm{SO}_{4}$ was added and the formation red-brown ring between two layers indicated the presence of triterpene in samples. The wider the ring, the higher the triterpene content.

\section{(xi) Detection of cardiac glycosides compound}

To detect the presence of cardiac glycosides in an extract solution, Keller-Killiani Test was performed. $0.1 \mathrm{~g}$ of QI extract powder was dissolved in $1 \mathrm{ml}$ distilled water. $0.4 \mathrm{ml}$ of glacial $\mathrm{CH}_{3} \mathrm{COOH}$ and few drops of $5 \% \mathrm{FeCl}_{3}$ were added into the extract mixture followed by 0.5 $\mathrm{ml}$ of concentrated $\mathrm{H}_{2} \mathrm{SO}_{4}$. The formation of brown ring confirmed the presence of cardiac glycosides. The wider the ring indicated the higher the cardiac glycosides content.

\section{Qualification of gallotannin using thin-layer chromatog- raphy (TLC)}

TLC separation was performed using aluminum sheets coated with silica gel 60 F254 (Merck Kga A, Darmstadt, Germany). $1 \mathrm{mg} / \mathrm{ml}$ QI extracts were prepared and spotted on the TLC plate. $1 \mathrm{mg} / \mathrm{ml}$ of synthetic gallotannin (Sigma, USA. Cat. No.: T0200) also was spotted on the same TLC plate as a positive control. The spotted TLC was let dried and put into a developing chamber added with chloroform: methanol: water (12:4:0.1). The TLC plate was removed once the solvent of the developing chamber almost reached the top of plate. Then, the plate was immediately viewed under short length wavelength ultraviolet (UV) light $(254 \mathrm{~nm})$ and long-wavelength UV light $(365 \mathrm{~nm})$. The presence of bands on spotted TLC plate were observed and recorded.

\section{Quantification of gallotannin using high-performance liquid chromatography (HPLC)}

The concentration of gallotannin active compound in both extracts were analysed using HPLC. $1 \mu \mathrm{g}$ of QI extracts were dissolved in $1 \mathrm{ml}$ of methanol. Then the mixture was filtered using $0.2 \mu \mathrm{m}$ nylon filter membrane and injected into the HPLC system. The samples were analysed using Nexera XR LC -20 AD XR Compact LC System and consisted of SPD-M20A Photodiode Array Detectors, Prominence SIL20A/AC Auto samplers, CBM-20A Communication Bus Module and Prominence CTO-20A Column oven. A Shim-pack GIST C18 HPLC Packed column of $250 \times 4.6 \mathrm{~mm}, 5 \mu \mathrm{m}$ (Shimadzu, Japan) maintained at $35^{\circ} \mathrm{C}$ was used as separation column. Elution was carried out with $1 \%$ acetic acid (solvent $\mathrm{A}$ ) - methanol (solvent $\mathrm{B}$ ) gradient: started with $95 \%$ solvent $A$ and ended with $5 \%$ solvent $B$. The gradient solvent was pumped sequentially at flow rate of $1 \mathrm{ml} / \mathrm{min}$ and the column temperature was always maintained at ambient temperature. Synthetic gallotannin at gradient concentrations were used as standard marker in this assay. Finally, peak was identified at $280 \mathrm{~nm}$ and full UV spectra were recorded from 200 to $364 \mathrm{~nm}$. By using the calibration curve obtained from the standard marker, the concentration of gallotannin content in QI extract samples were determined.

\section{Determination of antioxidant activity using DPPH free radical scavenging assay}

DPPH (2,2-diphenyl-1-picryl-hydrazyl-hydrate) assay was performed according to previously described method ${ }^{16}$ with slight modifications. Both QI extracts and synthetic gallotannin (positive control) were serially diluted with methanol to $2,4,6,8,10 \mu \mathrm{g} / \mathrm{ml}$, respectively. The diluted samples were added with $100 \mu \mathrm{l}$ of $0.1 \mathrm{mM} \mathrm{DPPH}$ and incubated in dark at room temperature for 30 minutes. DPPH free radical was reduced in the presence of antioxidant molecule, changing color from purple to yellow. The optical density (OD) of samples were determined at $517 \mathrm{~nm}$. The free radical scavenging activity of the QI extracts were calculated using the following formula:
Radical Scavenging Activity $(\%)=\frac{O D \text { Control }-O D \text { sample }}{O D \text { Control }} \times 100$
RESULTS

\section{Yield of crude extracts}

From $50 \mathrm{~g}$ of QI galls powder, $16.98 \mathrm{~g}$ (34.0\%) of crude extract powder was generated from methanol extraction, while only $9.45 \mathrm{~g}$ (18.9\%) crude extract powder was obtained from aqueous extraction.

\section{Phytochemical analysis}

Several phytochemical tests had been performed to comprehensively determine the presence of important bioactive compounds in both QI gall methanol and aqueous crude extracts. Observation and results for each test are recorded in Table 1. Based on the result obtained, we found that both QI gall methanol and aqueous extracts contained phenol and tannin. However, the major type of tannin presence in QI galls was gallotannin (hydrolysable tannin - presence) instead of phlobatannin (non-hydrolysable/condensed tannin - absence). To our knowledge, this is the first study reporting the solubility differences between hydrolysable and non-hydrolysable tannins in methanol and aqueous solvents, respectively. Based on this preliminary screening result, we focused on investigating the recovery of gallotannin (or also known as tannic acid) in all subsequent tests in this study.

Furthermore, it was also worth noting that the phytochemical constituents extracted using methanol and aqueous solvents were very much different. Methanol extract was found richer in flavonoid, while aqueous extract was found richer in phenol, tannin, gallotannin, triterpene and cardiac glycosides. Also, saponin, terpenoid and quinine only were found in aqueous extract, but absence in methanol extract. The similarity of both extracts was that both extracts were found absence of phlobatannin and alkaloid. These findings provide preliminary data for researcher to select solvent of choice based on their compound of interest.

\section{TLC and HPLC determination of gallotannin}

Crude extracts from methanol and aqueous extraction were loaded on TLC plate for the detection of tannin. Considering only gallotannin was found in the QI extracts, thus we focused on detecting gallotannin in the test. Based on the TLC result obtained under $254 \mathrm{~nm}$ ultraviolet light, gallotannin was observed in both crude extracts where the bands with the same retention factor (Rf) value as the standard gallotannin sample appeared (Figure 2, indicated by the red box). Besides, two additional bands which indicated unknown compounds were also found in the methanol crude extracts (Figure 2, indicated by the yellow box).

In order to verify the TLC results, HPLC test was performed. As expected, HPLC result confirmed the presence of gallotannin in both QI methanol and aqueous extracts as both the extracts showed the presence of elution peak identical to the standard gallotannin sample elution peak at retention time $2.85 \mathrm{~min}$ (Figure 3). There was an unknown prominent peak appeared before the gallotannin peak. It could be due to the oxidation of samples during the test process. In addition, the presence of an additional unknown compound was also detected in crude methanol extract at retention time of $3.12 \mathrm{~min}$. However, this additional compound was not detected in crude aqueous extract. To quantify gallotannin concentration in samples, a serial diluted standard gallotannin was used to plot a standard calibration curve. Based on the standard curve analysis, QI aqueous solvent yielded significant higher gallotannin content $(75.0 \mu \mathrm{g} / \mathrm{ml})$ compared to QI methanol solvent $(46.8 \mu \mathrm{g} / \mathrm{ml})$. 
Table 1: Summary of all relative qualitative phytochemical analysis test results for QI gall methanol and aqueous crude extracts. (- indicates negative result; + indicates positive result; ++ indicates stronger positive result).

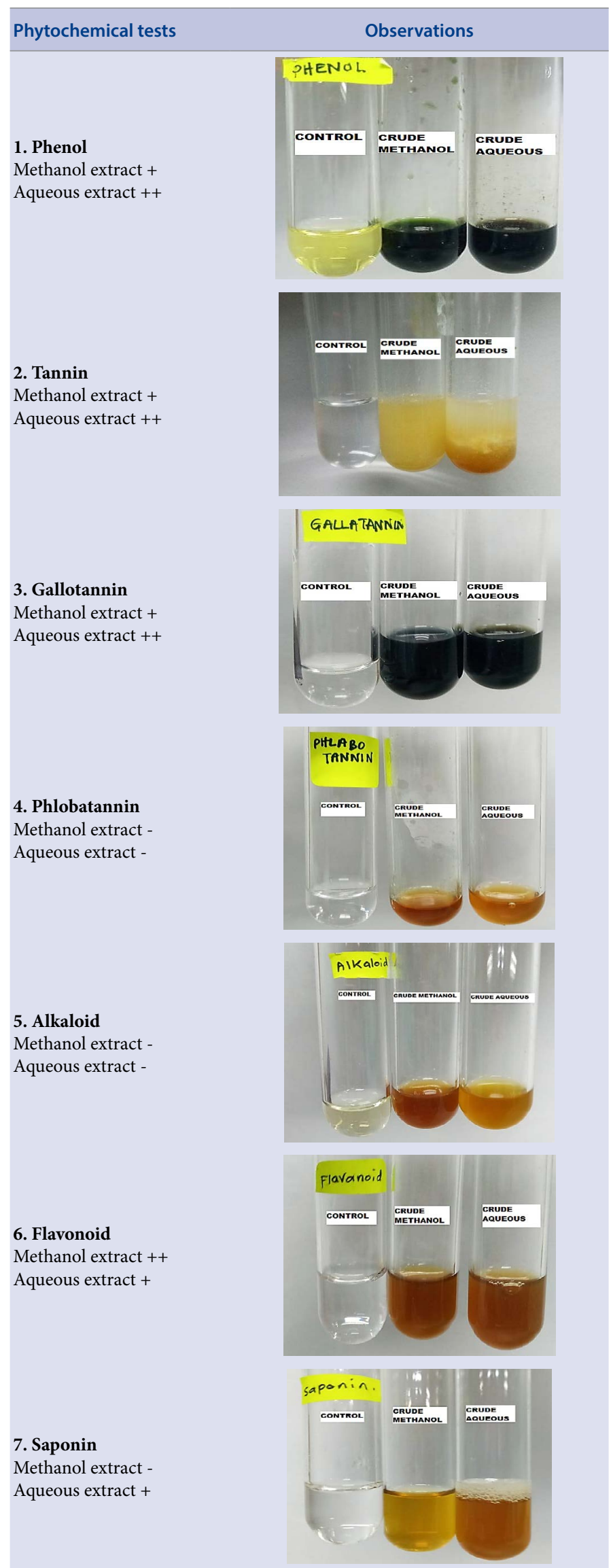

8. Terpenoid

Methanol extract -

Aqueous extract +

\section{Quinine}

Methanol extract -

Aqueous extract +

\section{Tritepene}

Methanol extract +

Aqueous extract ++

11. Cardiac glycosides

Methanol extract ++

Aqueous extract +
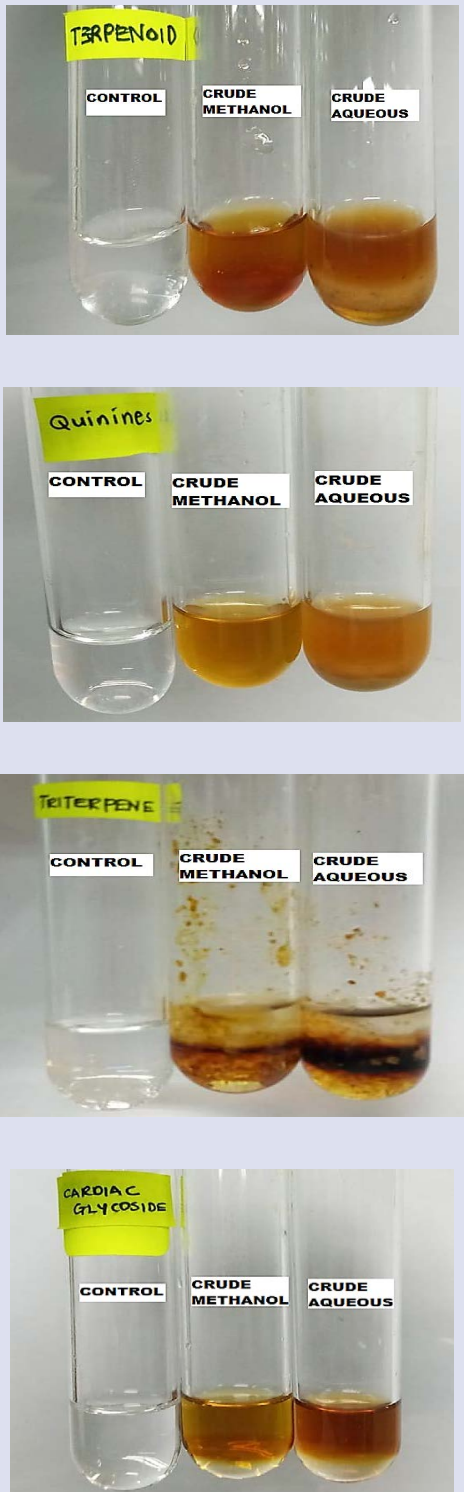

\section{Free Radical Scavenging Activity}

To determine the effectiveness of crude extract from methanol and aqueous extraction as an antioxidant agent, DPPH assay was performed. It was found that, from the lowest concentration $(2 \mu \mathrm{g} /$ $\mathrm{ml})$ to the highest concentration $(10 \mu \mathrm{g} / \mathrm{ml})$, both QI aqueous and methanol extracts successfully showed high anti-oxidant activities which were comparable to the synthetic gallotannin compound antioxidant activity (Figure 4). This indicated that gallotannin compound extracted from QI was highly effective as an anti-oxidant agent. The QI aqueous extract showed significant higher anti-oxidant potential as compared to the synthetic gallotannin compound (1.5-fold) and QI methanol extract (1.2-fold) at $2 \mu \mathrm{g} / \mathrm{ml}$, indicating that aqueous solvent was more efficient in generating extract with high anti-oxidant potential as compared to methanol solvent and even the synthetic pure gallotannin compound.

\section{DISCUSSION}

\section{Effects of different solvents on extraction yield}

In the present study, the biological content and anti-oxidant property of a local medicinal plant known as QI gall was investigated. Extraction is the crucial first step in the analysis of biological content in medicinal plants. There are many factors that play a critical role in the successful 


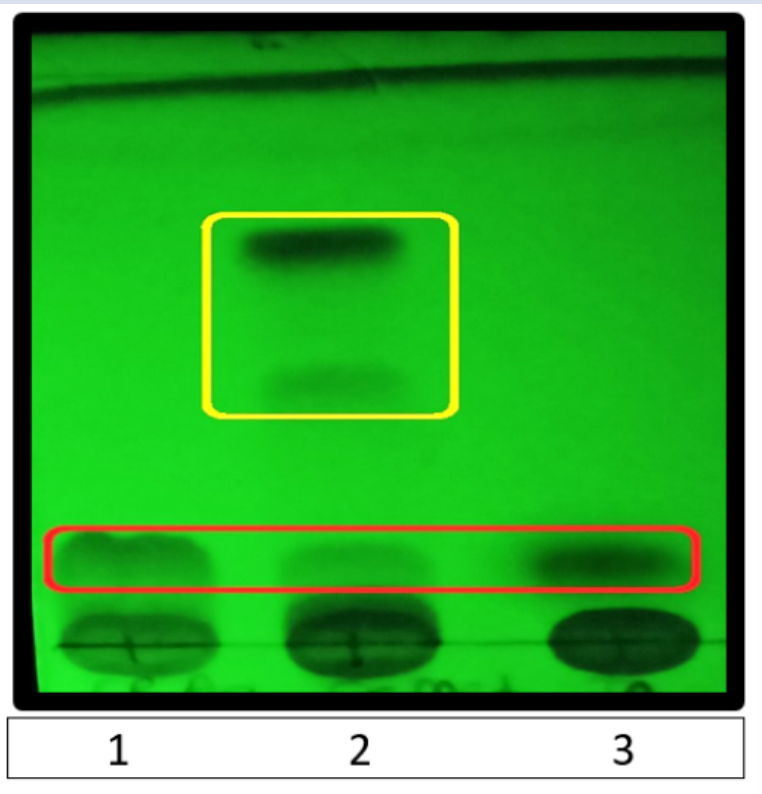

Figure 2: TLC analysis of QI extracts using short-wavelength $254 \mathrm{~nm}$ of ultraviolet light. Lane 1: synthetic gallotannin (standard marker), Lane 2: QI methanol crude extract, and Lane 3: QI aqueous crude extract. Each sample was loaded with the same equal concentration of $1 \mathrm{mg} / \mathrm{ml}$. As compared to the standard marker, gallotannin was confirmed present in both methanol and aqueous crude extracts (indicated by the red box). Two unknown compounds were also found in methanol crude extracts (indicated by the yellow box).

(A) mau

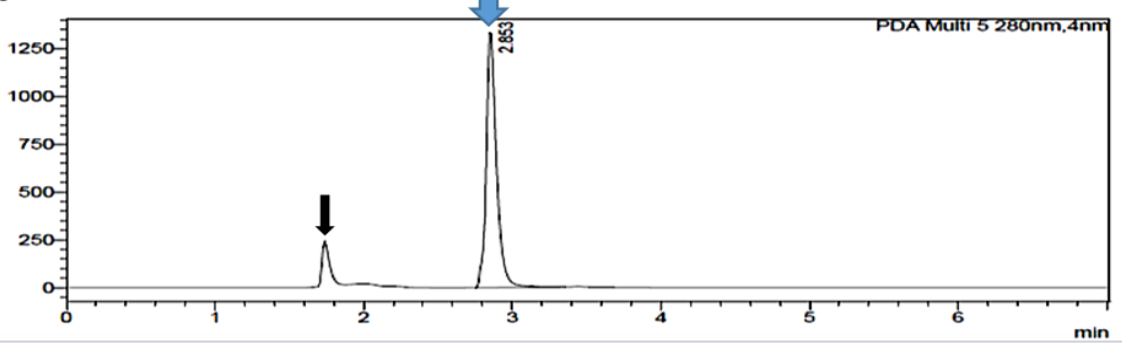

(B) maU

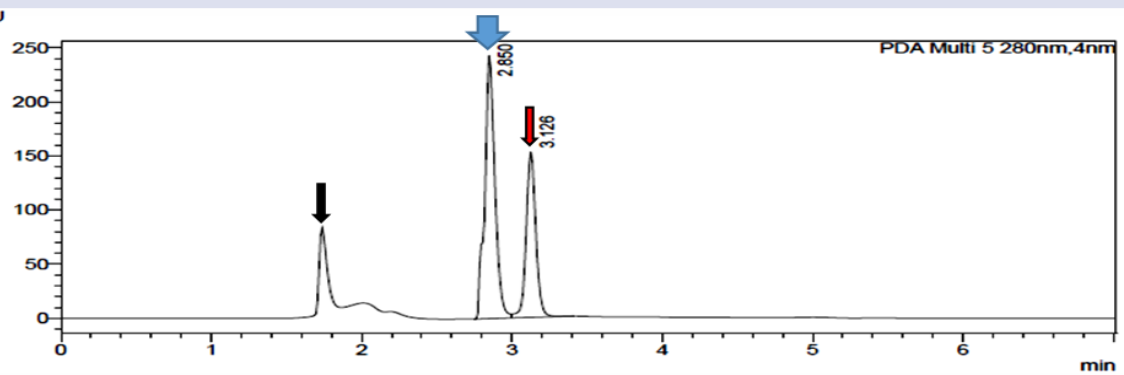

(C) maU

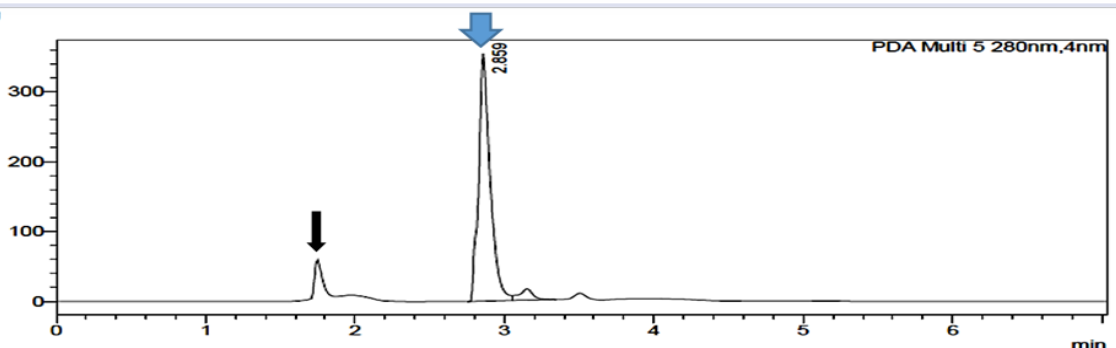

Figure 3: HPLC Chromatogram of (A) synthetic gallotannin as positive control and (B) QI methanol crude extract and (C) QI aqueous crude extract. Each sample was injected at an equal amount of $1 \mathrm{ul} / \mathrm{min}$. The presence of gallotannin was observed in both Ql extracts at retention time $2.85 \mathrm{~min}$ (as indicated by blue arrows). The presence of an additional unknown compound was also detected in crude methanol extract at retention time of 3.12 min (as indicated by red arrow). The unknown prominent peak appeared before the gallotannin peak could be the oxidation of samples during process of samples (as indicated by black arrows). 


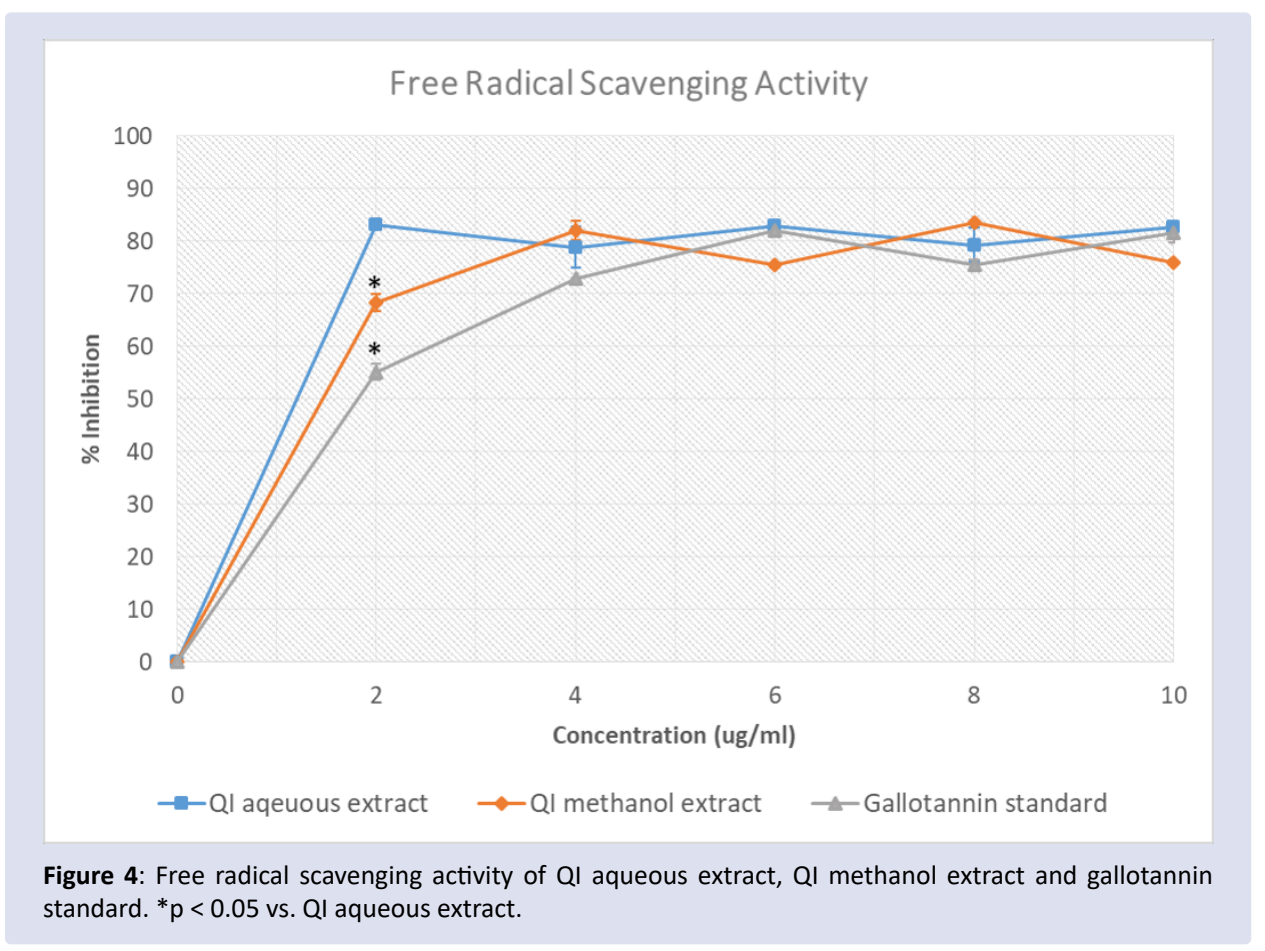

extraction of desired compounds from plant materials. Among them, the choice of solvent is the most significant factor. This is because, during the extraction procedure, the solvent would diffuse into the solid plant tissue and solubilize the compounds to extract them. Without a good solvent with low toxicity and high efficiency, the extraction of compound would not be possible. In order to extract different active compounds from QI galls with a high degree of efficacy and accuracy, solvents with different polarities were used and compared in this study. We found that methanol solvent generated significant higher yield of crude extract powder compared to water solvent. The result of this study is in agreement with the extraction yields of some medicinal 17 and ethnoveterinary plants ${ }^{18}$ reported in previous studies. These findings are not surprising, given that most of the active components in plant are saturated organic molecules which are non-polar. Thus, methanol being a less polar solvent than water could be more effective in extracting higher yield of non-polar biological compounds from plant material. This data also was supported by our TLC result which showed extra components with larger Rf value (which indicated nonpolarity) detected in the QI methanol extract.

Nonetheless, being more doesn't always mean the merrier. In order to better understand the effect of solvents on extraction yield, further phytochemical analysis was performed to determine the content of bioactive compounds in the extract. In accordance with the different extraction yields, the content of bioactive compounds also was found varied amongst the extracts. Methanol extract was found richer in flavonoid, while aqueous extract was found richer in phenol, tannin, gallotannin, triterpene and cardiac glycosides. Further, the observed differences between the two extracts was the absence of saponin, terpenoid and quinine in the methanol extract. These three active compounds only were found in the aqueous extract. This can be attributable to the different solubility of these compounds in the solvents tested. According to Ghasemzadeh et al., the selection of solvent system largely depends on the specific nature of the bioactive compound being targeted ${ }^{19}$. Different solvent systems are available to extract different bioactive compound from natural products. For instance, many flavonoids dissolve poorly in water but readily dissolve in organic solvents, such as methanol, diethyl ether, chloroform or 1,2-dichloroethan. ${ }^{17}$ This is in agreement with the result presented in study in which flavonoid was found richer in methanol extract as compared to aqueous extract. Therefore, it is imperative to perform extraction solvent and phytochemical screening prior to any natural product isolation procedure to ensure optimum quality and quantity of desired extract.

\section{Identification and quantification of tannin}

On the other hand, phenol was found richer in aqueous extract compared to methanol extract based on phytochemical screening observation in present study. Phenol is a family of the most abundantly found secondary metabolites in plants. It is broadly distributed in the plant kingdom and has drawn increasing attention due to their potent antioxidant properties and medicinal effects in preventing various oxidative stress associated diseases such as cancer. ${ }^{20}$ There are many types of phenols, and tannin is one of the well-known phenolic compound presents in QI galls. We further confirmed the major types of tannin found in QI galls was hydrolysable gallotannin instead of non-hydrolysable phlobatannin. Hydrolysable and non-hydrolysable tannins are different structurally in which the former are richly hydroxlyated oligomers of gallic acid while the latter are polymers rich in flavan-3-ols such as catechin. ${ }^{21}$ Functionally, both types of tannins also shows differences in the aspect of anti-cancer, anti-inflammatory, anti-microbial and cardiovascular protection. ${ }^{22}$ Thus, the findings presented in this study provided an important insight to be considered during the future exploitation of QI galls for medical usage.

In order to verify the preliminary phytochemical screening results, further identification and quantification of gallotannin compound were performed in this study using TLC and HPLC techniques. TLC is a procedure to identify different components in a mixture based on the Rf value, while HPLC is a more robust technique to quantify a particular component in a mixture based on the retention time and elution peak width. We had successfully identified gallotannin compound in both QI extracts in present study and confirmed that the gallotannin concentration was significantly higher in aqueous extract as compared to methanol extract. This indicated that aqueous solvent is more efficient to extract the desired gallotannin compound despite the overall yield percentage was lower than methanol solvent. For the basis of traditional uses, water solvent is commonly used to mimic as closely 
as possible the process by which traditional herbal drug is prepared by the traditional healer. Moreover, considering the potential hazards of organic solvents, water is considered much safer than methanol for human consumption. Therefore, this study strongly recommends to use aqueous solvent for recovery of tannin, particularly the gallotannin compound from QI galls.

\section{Anti-oxidant activities of QI extracts}

The choice of solvent for extraction is crucial for the overall success of natural product isolation. Besides choosing the solvent type which can yield higher percentage of desired compound, considerations must be taken to assure that the biological activities of plant constituents are not lost, distorted or destroyed during the preparation of the extract from the plant materials using the selected solvent. In this study, DPPH radical scavenging assay was used to evaluate and compare the antioxidant potential of QI gall aqueous and methanol extract, respectively. The basic concept of free radical scavenging activity is the ability of an antioxidant agent to donate electron to a free radical and produce a more stable and thus less harmful radical structure. Among the extracts tested, the aqueous extract was the most potent agent in DPPH scavenging activity. This could be due to the higher level of phenolic gallotannin compounds with powerful antioxidant activity in this extract. ${ }^{23}$ Remarkably, the aqueous extract of QI also exhibited a 1.5 -fold higher DPPH scavenging activity than the synthetic pure gallotannin compound. Although the full characterization profile of QI aqueous extract is yet to be elucidated, we proposed that the observed effect is probably due to the synergistic effects of other active compounds present in the QI aqueous extract such as triterpene, cardiac glycosides saponin, terpenoid and quinine. These organic active compounds presence in the QI aqueous extract may aid in the DPPH scavenging activity, making QI aqueous extract a better antioxidant agent as compared to the single pure gallotannin compound.

\section{CONCLUSION}

This study determine the optimal extraction solvent to extract tannin compound from a natural medicinal plant, QI galls. As suggested by the strong correlation between the antioxidant activity and phenolic content, the antioxidant capacity of the QI extracts can be mainly attributed to the presence of tannin, particularly the gallotannin active compound found in the QI galls. This study revealed QI aqueous solvent yielded significant higher gallotannin content compared to QI methanol solvent. Besides, the QI aqueous extract also showed significant higher anti-oxidant potential as compared to the QI methanol extract. Taken together, these data indicated that water is a better solvent for extraction of QI galls with improved gallotannin yield and enhanced antioxidant activity. Moreover, considering water boiling is also a nontoxic traditional approach for herb drink preparation, therefore, this study strongly support the utilization of water solvent for optimum gallotannin extraction from QI galls in future study.

\section{ACKNOWLEDGMENTS}

This study was funded by the Ministry of Higher Education Malaysia for Fundamental Research Grant Scheme with Project Code: FRGS/2/2013/ SKK01/USM/03/1. We thank Universiti Sains Malaysia (USM) for the support in granting permission to the investigators to use the space and assets belonging to the university during the process of conducting the research.

\section{AUTHOR CONTRIBUTIONS}

Nur Alisa Kamarudin: Analysis and interpretation of data; Drafting the article.

Norhazilah Muhamad: Analysis and interpretation of data; Final approval of the article.
Nik Nur Hakimah Nik Salleh @ Nik Abdullah: Analysis and interpretation of data; Final approval of the article

Suat Cheng Tan: Conception and design; Revising the article critically; Final approval of the article.

\section{REFERENCES}

1. Sen T, Samanta SK. Medicinal plants, human health and biodiversity: A broad review. Advances in Biochemical Engineering/ Biotechnology. 2014. doi:10.1007/10_2014_273

2. Casagrande M, Zanela J, Wagner A, et al. Influence of time, temperature and solvent on the extraction of bioactive compounds of Baccharis dracunculifolia: In vitro antioxidant activity, antimicrobial potential, and phenolic compound quantification. Industrial Crops and Products. 2018. doi:10.1016/j.indcrop.2018.08.088

3. Chokpaisarn J, Chusri S, Amnuaikit T, Udomuksorn W, Voravuthikunchai SP. Potential wound healing activity of Quercus infectoria formulation in diabetic rats. PeerJ. 2017. doi:10.7717/ peerj.3608

4. Askari SF, Azadi A, Jahromi BN, et al. A comprehensive review about Quercus infectoria G. Olivier gall. Research Journal of Pharmacognosy (RJP). 2020. doi:10.22127/rjp.2019.184177.1494

5. Kheirandish F, Delfan B, Mahmoudvand H, et al. Antileishmanial, antioxidant, and cytotoxic activities of Quercus infectoria Olivier extract. Biomedicine and Pharmacotherapy. 2016. doi:10.1016/j. biopha.2016.04.040

6. Ou L, He Q, Ji Z, Li K, Tian S. Quantitative high-performance thin-layer chromatographic analysis of three active compounds in gall of Quercus infectoria Olivier (fagaceae) and use of thin-layer chromatography-2,2-diphenyl-1-picrylhydrazyl to screen antioxidant component. Journal of Planar Chromatography - Modern TLC. 2015. doi:10.1556/1006.2015.28.4.6

7. Shrestha S, Kaushik VS, Eshwarappa RSB, Subaramaihha SR, Ramanna LM, Lakkappa DB. Pharmacognostic studies of insect gall of Quercus infectoria Olivier (Fagaceae). Asian Pacific Journal of Tropical Biomedicine. 2014. doi:10.1016/S2221-1691(14)60205-7

8. Kopjar M, Tadić M, Piližota V. Phenol content and antioxidant activity of green, yellow and black tea leaves. Chemical and Biological Technologies in Agriculture. 2015. doi:10.1186/s40538-014-0028-7

9. Heinonen M. Antioxidant activity and antimicrobial effect of berry phenolics - A Finnish perspective. Molecular Nutrition and Food Research. 2007. doi:10.1002/mnfr.200700006

10. Mercurio MD, Smith PA. Tannin quantification in red grapes and wine: Comparison of polysaccharide- and protein-based tannin precipitation techniques and their ability to model wine astringency. Journal of Agricultural and Food Chemistry. 2008. doi:10.1021/ jf8008266

11. War AR, Paulraj MG, Ahmad T, et al. Mechanisms of plant defense against insect herbivores. Plant Signaling and Behavior. 2012. doi:10.4161/psb.21663

12. Macáková K, Kolečkář V, Cahlíková L, et al. Tannins and their Influence on Health. In: Recent Advances in Medicinal Chemistry. ; 2014. doi:10.1016/B978-0-12-803961-8.50006-3

13. Altemimi A, Lakhssassi N, Baharlouei A, Watson DG, Lightfoot DA Phytochemicals: Extraction, isolation, and identification of bioactive compounds from plant extracts. Plants. 2017. doi:10.3390/ plants6040042

14. Cheng TS, Balachandran L, Mohamad N, et al. The potential of neural stem cell as vehicle to deliver quercus infectoria extract to glioma cell In vitro. Sains Malaysiana. 2018. doi:10.17576/jsm2018-4706-16

15. SatyaEswari J, Dhagat S, Naik S, Dibya S. Oroxylum indicum leaf extracts for screening of antimicrobial properties and phytochemicals. Pharmaceutical Bioprocessing. 2018. 
16. Miliauskas G, Venskutonis PR, Van Beek TA. Screening of radical scavenging activity of some medicinal and aromatic plant extracts. Food Chemistry. 2004. doi:10.1016/j.foodchem.2003.05.007

17. Truong DH, Nguyen DH, Ta NTA, Bui AV, Do TH, Nguyen HC. Evaluation of the use of different solvents for phytochemical constituents, antioxidants, and In vitro anti-inflammatory activities of severinia buxifolia. Journal of Food Quality. 2019. doi:10.1155/2019/8178294

18. Mudzengi CP, Murwira A, Tivapasic M, Murungweni C, Burumue $J$ V., Halimani T. Antibacterial activity of aqueous and methanol extracts of selected species used in livestock health management. Pharmaceutical Biology. 2017. doi:10.1080/13880209.2017.1287744

19. Ghasemzadeh A, Jaafar HZE, Rahmat A. Effects of solvent type on phenolics and flavonoids content and antioxidant activities in two varieties of young ginger (Zingiber officinale Roscoe) extracts. Journal of Medicinal Plants Research. 2011.
20. Dai J, Mumper RJ. Plant phenolics: Extraction, analysis and their antioxidant and anticancer properties. Molecules. 2010. doi:10.3390/molecules15107313

21. Martinez KB, Mackert JD, Mclntosh MK. Polyphenols and Intestinal Health. In: Nutrition and Functional Foods for Healthy Aging. ; 2017. doi:10.1016/B978-0-12-805376-8.00018-6

22. KoleckarV, KubikovaK, RehakovaZ, etal.CondensedandHydrolysable Tannins as Antioxidants Influencing the Health. Mini-Reviews in Medicinal Chemistry. 2008. doi:10.2174/138955708784223486

23. Rebaya A, Belghith SI, Baghdikian B, et al. Total Phenolic, Tota Flavonoid, Tannin Content, and Antioxidant Capacity of Halimium halimifolium (Cistaceae). Journal of Applied Pharmaceutical Science. 2015. doi:10.7324/JAPS.2015.50110

\section{GRAPHICAL ABSTRACT}

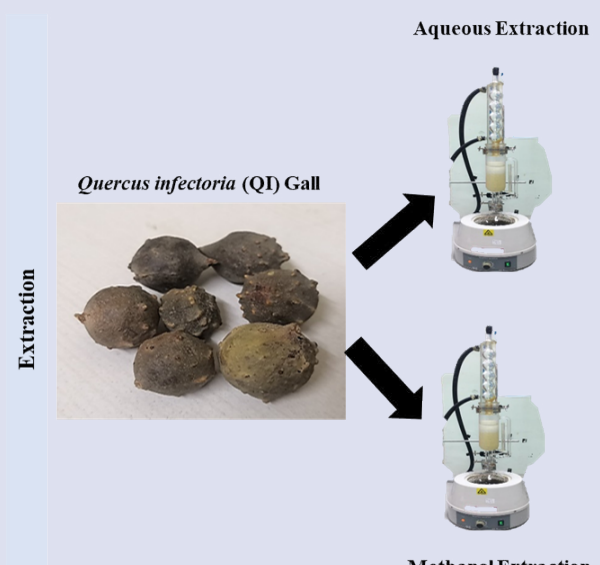

MethanolExtraction

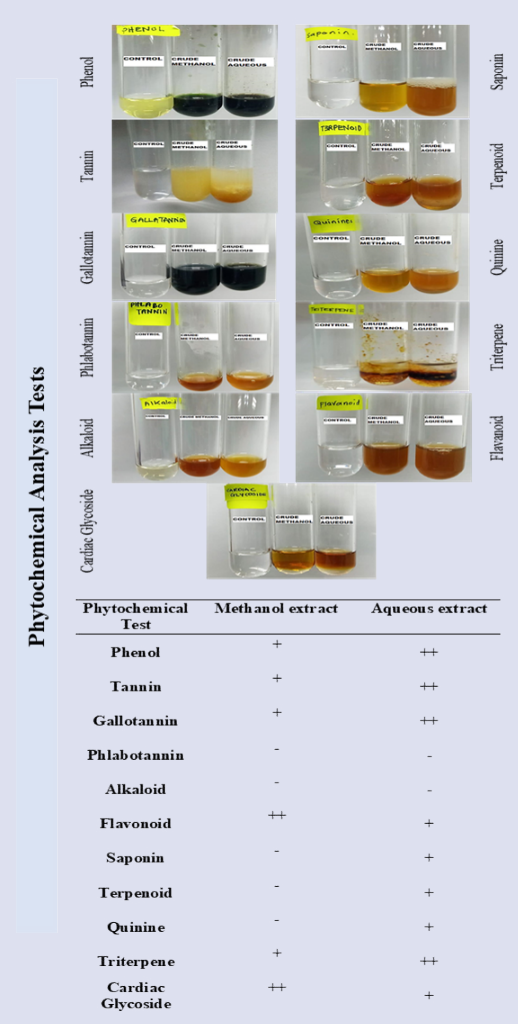

Quantitative Analysis of Antioxidant Compound (Gallotannin) in QI Extracts

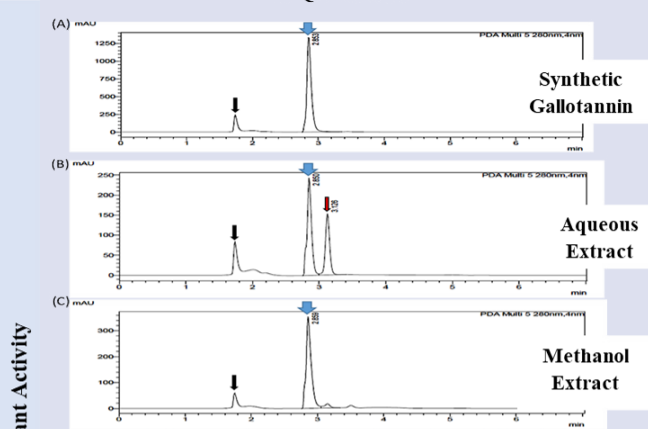

Arrow indicator: Blue $=$ gallotannin; Red $=$ additional unknown compound: Black = oxidation of samples during process of samples.

Free Radical Scavenging Activity of QI Extracts

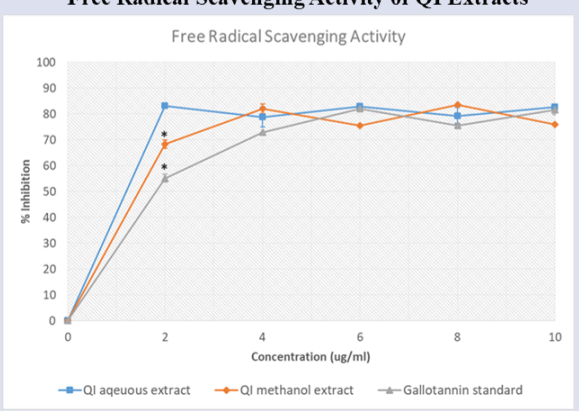




\section{ABOUT AUTHORS}

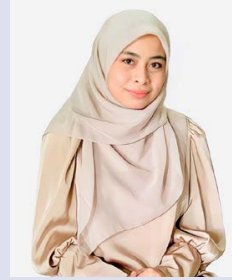

Nur Alisa Kamarudin obtained her Bsc (Hons.) in Biotechnology Resources from Universiti Malaysia Sarawak in 2018. Currently, she pursues her Master's degree at School of Health Sciences, Science University of Malaysia (USM) under the supervision of Dr. Tan Suat Cheng. Alisa's study focused on the therapeutic potential of Quercus infectoria for human brain cancer and preconditioned neural stem cells for ischemic stroke treatment.

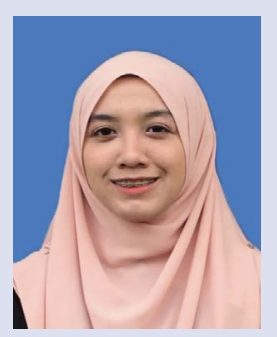

Nik Nur Hakimah Nik Salleh obtained her Bsc. (Hons.) in Science (Biology) at Universiti Teknologi MARA (UITM) Shah Alam in 2017 and joined School of Health Sciences in Universiti Sains Malaysia (USM) as a research assistant (RA) in 2018. Nik Nur Hakimah is currently a MSc. Candidate in Biomedicine and her research interests constitute on isolation of bioactive compound from natural plants, neural stem cell cultures and ischemic stroke induction via the endothelin-1 pathway.

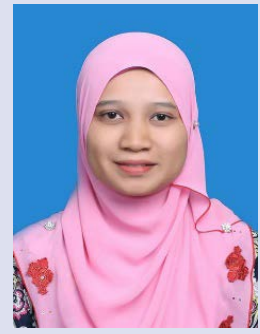

Norhazilah Muhamad is a Lecturer of Anatomy at Faculty of Medicine, Universiti Sultan Zainal Abidin (UniSZA), Malaysia. She received her B.Sc. (Hons.) in Biomedical Science in 2006 and MMed. Science (Anatomy) in 2012 from National University of Malaysia (UKM). Currently she is a PhD candidate of Molecular and Cell Biology at School of Health Sciences, Science University of Malaysia (USM). She has published a number of articles in scientific journals. Her research interests are in the field of natural product discovery for cancer therapies and diabetic wound healing.

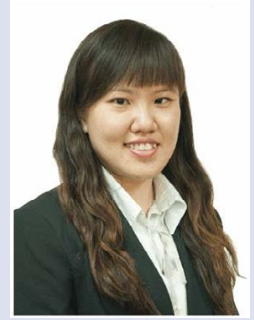

Dr. Tan Suat Cheng obtained her B Sc (honours) in Biotechnology at School of Science and Technology, Universiti Malaysia Sabah in 2007 and D.Phil at Department of Physiology, Anatomy and Genetic (DPAG), University of Oxford in 2011. Currently, she is senior lecturer of Biomedicine Program at School of Health Sciences, Science University of Malaysia (USM). Dr. Tan's research focuses on the development of reliable neural stem cell-based therapeutic technique to treat ischemic stroke disease. She is also interested to establish stem cell-based biological delivery vehicle for the delivery of anti-cancer compounds isolated from medicinal plants in the targeted anti-cancer therapy.

Cite this article: Kamarudin NA, Muhamad N, Salleh NNHN, Tan SC. Impact of Solvent Selection on Phytochemical Content, Recovery of Tannin and Antioxidant Activity of Quercus Infectoria Galls. Pharmacogn J. 2021;13(5): 